\title{
Magnetostructural Correlations of Nano-Sized Manganites Prepared by Different Ways
}

\author{
M. VAvra ${ }^{a, b, *}$, Marián Mihalik ${ }^{a},{\text { Matúš } \text { Mihalik }^{a}, \text { M. ZentKováa }}^{a}$, J. Lazurováa ${ }^{a}$, \\ M. MATIK ${ }^{c}$, J. BRIANČIN ${ }^{c}, Z$ Z. ARNOLD ${ }^{d}$, M. MARYŠKO ${ }^{d}$ \\ ${ }^{a}$ Institute of Experimental Physics SAS, Watsonova 47, 04001 Košice, Slovakia \\ ${ }^{b}$ Institute of Chemistry, Faculty of Science, P. J. Šafarik University, Moyzesova 11, 04154 Košice, Slovakia \\ ${ }^{c}$ Institute of Geotechnics SAS, Watsonova 45, 04001 Košice, Slovak Republic \\ ${ }^{d}$ Institute of Physics AS CR v.v.i., Na Slovance 2, 18221 Prague, Czech Republic
}

We present the preparation and magnetostructural correlations of binary $\mathrm{NdMnO}_{3}$ oxide prepared by four different procedures. Nano-size particle were prepared by simple precipitation of hydroxides (PH), nitrate-glycine synthesis (NG) and self-combustion high-temperature synthesis (SHS), while sol-gel method (SG) produced particles with size of about $2 \mu \mathrm{m}$. The as prepared PH and SG particles exhibit amorphous structure, the orthorhombic crystal structure was observed for NG and SHS particles. As prepared PH, NG and SHS are magnetically ordered, annealing leads to magnetic ordering of SG particles.

DOI: $10.12693 /$ APhysPolA.126.304

PACS: 75.50.--y, 75.47.Lx, 75.30.-m, 75.75.-c, 68.37.Hk, 61.05.cp

Binary oxides of general $\mathrm{ABO}_{3}$ composition (A and $\mathrm{B}$ are metal cations) usually crystallize in two exemplar structural models. These models are based on the structure of two minerals: ilmenite-FeTiO ${ }_{3}$ and perovskite$\mathrm{CaTiO}_{3}$. They differ between each other in the ionic radii of $\mathrm{A}$ and $\mathrm{B}$ cations. When the radii are nearly the same, the ilmenite-like structure could be observed and when the radii are of very different sizes, the perovskitelike structure could be expected. Manganites (atom B is manganese) are frequently studied for their interesting magnetic properties and a particular interest is paid to study of nano-sized particles [1]. In our paper we present the preparation and characterization of $\mathrm{NdMnO}_{3}$ compound prepared by four different procedures.

$\mathrm{NdMnO}_{3}$ adopts the perovskite-like orthorhombic structure (space group P nma) [2]. Magnetic properties of $\mathrm{NdMnO}_{3}$ are mostly determined by $\mathrm{Mn}-\mathrm{Mn}$ and $\mathrm{Mn}$ Nd magnetic interactions. The Mn sublattice orders antiferromagnetically at $T_{N}=82 \mathrm{~K}$ with magnetic moments parallel to $b$-axis. This ordering is ascribed to the superexchange between $\mathrm{Mn}$ ions mediated by oxygen atoms [3]. Magnetic interaction of Nd-Mn sublattice leads to ferromagnetic ordering (moments parallel to $c$ axis) only at temperatures lower than $20 \mathrm{~K}[2,4]$, as a consequence of the polarization of $\mathrm{Nd}^{3+}$ ions by the manganese ions.

$\mathrm{NdMnO}_{3}$ samples were prepared in a wet way by different procedures: 1 . simple precipitation of hydroxides $(\mathrm{PH}), 2$. sol-gel method (SG) [5], 3. nitrate-glycine synthesis (NG) [1] or 4. self-combustion high-temperature synthesis (SHS) [6]. The as prepared samples were annealed at $600{ }^{\circ} \mathrm{C}$ for 2 hours. Scanning electron mi-

\footnotetext{
* corresponding author; e-mail: vavra@saske.sk
}

croscope (SEM) photos were taken by MIRA3 TESCAN, X-ray powder diffraction pattern, by a BRUKER diffractometer in Bragg-Brentano configuration using $\mathrm{Cu}$ $\mathrm{K}_{\alpha 1, \alpha 2}$ doublet radiation. Magnetization measurements were performed by MPMS in the range from $2 \mathrm{~K}$ to $350 \mathrm{~K}$ and in magnetic fields up to $5 \mathrm{~T}$.

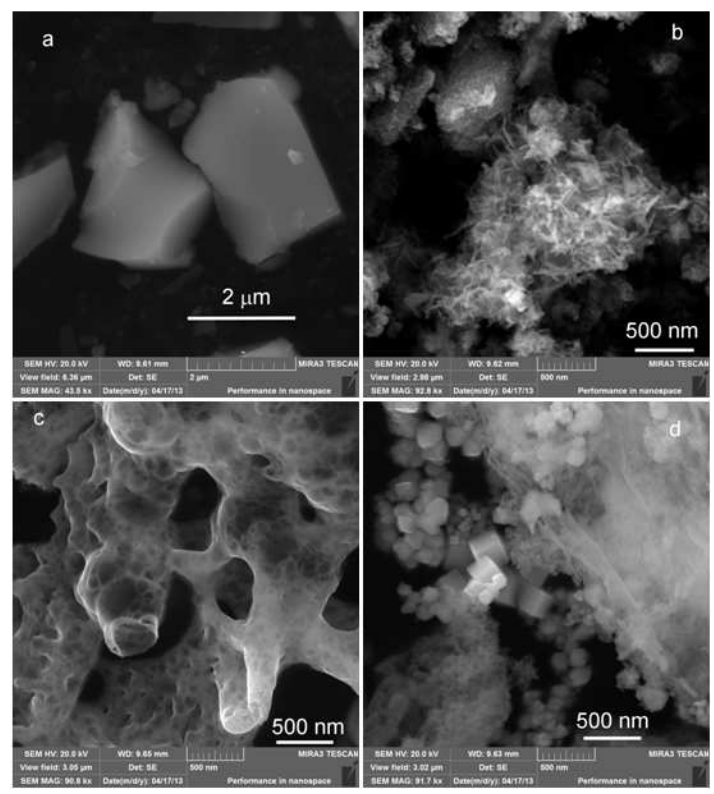

Fig. 1. SEM photos taken from as prepared samples, which were synthetized by a) sol-gel, b) precipitation, c) nitrate-glycine and d) SHS methods.

Nano-size particles were prepared by $\mathrm{PH}$ synthesis and by NG or SHS high-temperature synthesis, while the as prepared SG particles have average size of about $2 \mu \mathrm{m}$ (Fig. 1). The as prepared PH and SG particles exhibit amorphous structure. The orthorhombic crys- 


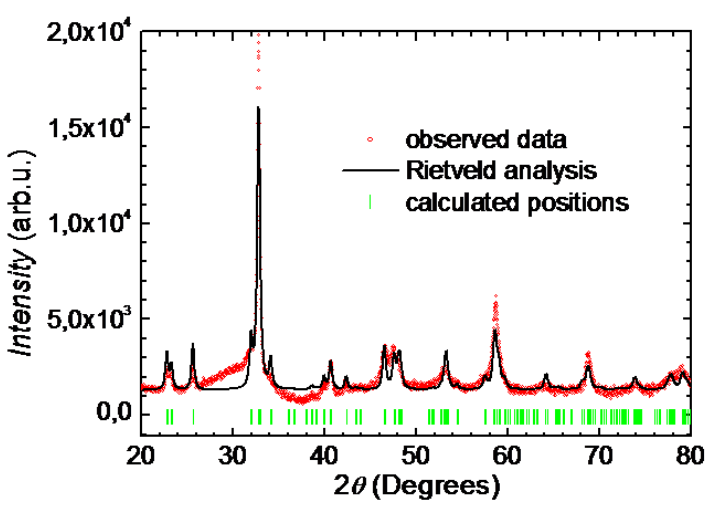

Fig. 2. X-ray powder diffraction pattern was taken from as prepared sample, which was synthetized by SHS method.

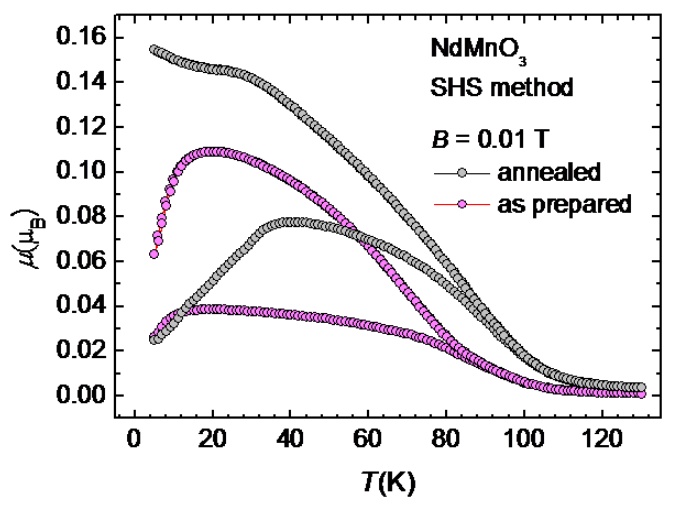

Fig. 3. ZFC and FC magnetization curves of SHS samples.

tal structure (space group $\mathrm{P} n m a$ ) was observed for NG $(a=0.5679 \mathrm{~nm}, b=0.7670 \mathrm{~nm}, c=0.5429 \mathrm{~nm})$ and SHS particles $(a=0.6411 \mathrm{~nm}, b=0.7617 \mathrm{~nm}, c=0.4827 \mathrm{~nm})$. Nanoparticles have a wide size distribution (Fig. 1) and an amorphous background (Fig. 2). Annealing reduces volume of elementary cell e.g. from $0.23648 \mathrm{~nm}^{3}$ to $0.23069 \mathrm{~nm}^{3}$ in the case of NG particles.

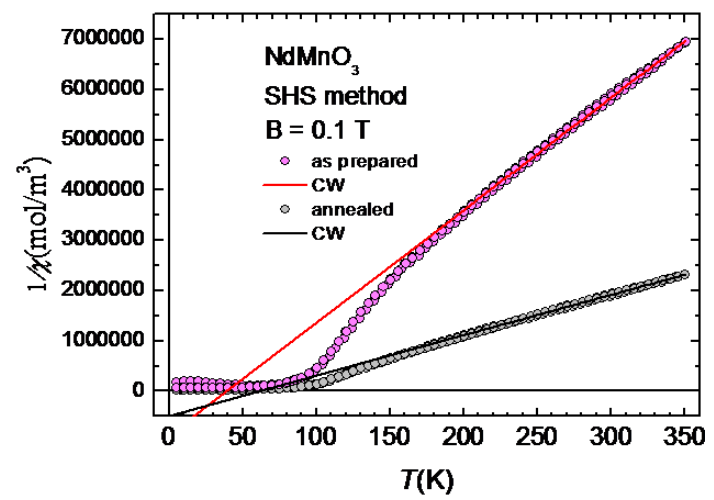

Fig. 4. Fit to the Curie-Weiss law for SHS samples.

The as prepared $\mathrm{PH}, \mathrm{NG}$ and SHS particles undergo magnetic phase transition at $42.3 \mathrm{~K}, 36.1 \mathrm{~K}$ and $71.1 \mathrm{~K}$ respectively, while SG particles are paramagnetic down to the lowest temperatures. Hysteretic behavior between magnetization measured in zero-field cooled and field cooled regimes is typical feature of all samples (Fig. 3). Temperature of the magnetic phase transition increases with annealing (Fig. 3) to $66 \mathrm{~K}, 63 \mathrm{~K}$ and $86 \mathrm{~K}$ for $\mathrm{PH}$, $\mathrm{NG}$ and SHS particles respectively, while the magnetic transitions at $12.1 \mathrm{~K}$ and $29.5 \mathrm{~K}$ were observed in $\mathrm{SG}$ sample. The susceptibility data obey the Curie-Weiss law above $200 \mathrm{~K}$, with the effective magnetic moment $\mu_{e f f}=5.33 \mu_{B}$ and the paramagnetic Curie temperature $\theta=38.7 \mathrm{~K}$ for SHS as prepared particles.

Both parameters increase with annealing to $\mu_{\text {eff }}=$ $8.93 \mu_{B}$ and $\theta=61.4 \mathrm{~K}$. Different magnetic behavior of the SG sample can be explained by the different preparation, because only $\mathrm{SG}$ sample has been isolated from reductive environment of DL-malic acid [5].

Annealing expands hysteresis loop and increases saturated magnetization as it is demonstrated for NG particles (Fig. 5).

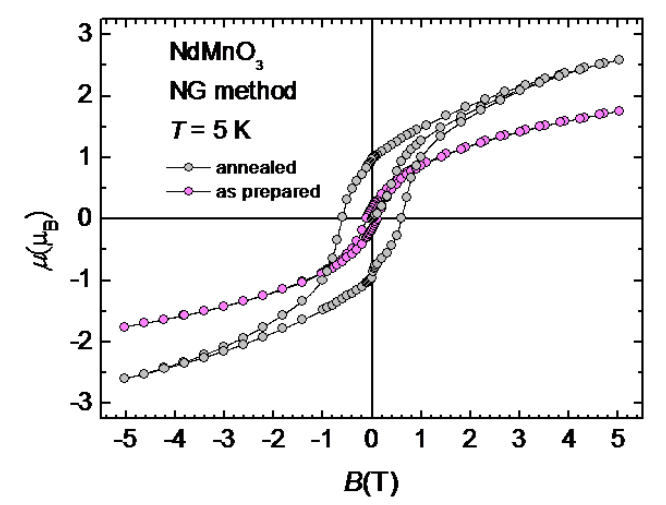

Fig. 5. Hysteresis loops were taken from the NG samples.

This work was supported by VEGA2/0178/13, APVV-0132-11, ERDF EU: No. ITMS26220120005 and ESF EU No. ITMS26220120034.

\section{References}

[1] D. Markovic, V. Kusigerski, M. Tadic, J. Blanusa, M.V. Antisari, V. Spasojevic, Scr. Mater. 59, 35 (2008).

[2] A. Muñnoz, J.A. Alonso, M.J. Martínez-Lope, J.L. García-Muñoz, M.T. Fernández-Díaz, J. Phys.: Condens. Matter 12, 1361 (2000).

[3] F. Bartolomé, J. Bartolomé, J. Campo, Phys. B 312 313, 769 (2002).

[4] T. Chatterji, B. Ouladdiaf, D. Bhattacharya, J. Phys.: Condens. Matter 21, 306001 (2009).

[5] G. Gritzner, J. Ammer, K. Kellner, V. Kavecansky, M. Mihalik, S. Matas, M. Zentkova, Appl. Phys. A 90, 359 (2008).

[6] A. Mrakovic, J. Blanusa, D. Primc, M. Perovic, Z. Jaglicic, V. Kusigerski, V. Spasojevic, Ceramics International 39, 3771 (2013). 